九州大学学術情報リポジトリ

Kyushu University Institutional Repository

Significance of homologous temperature in softening behavior and grain size of pure metals processed by high-pressure torsion

Edalati, Kaveh

Department of Materials Science and Engineering, Faculty of Engineering, Kyushu University

Horita, Zenj i

Department of Materials Science and Engineering, Faculty of Engineering, Kyushu University

http://hdl. handle. net/2324/25614

出版情報: Materials Science and Engineering A. 528 (25/26)，pp.7514-7523，2011-09-25. Elsevier バージョン:

権利関係 : (C) 2011 Elsevier B.V. 
Materials Science and Engineering A 528 (2011) 7514-7523

Received 30 December 2010, received in revised form 7 May 2011, accepted 25 June 2011.

Available online 2 July 2011.

\title{
Significance of homologous temperature in softening behavior and grain size of pure metals processed by high-pressure torsion
}

\author{
Kaveh Edalati*, Zenji Horita \\ Department of Materials Science and Engineering, Faculty of Engineering, Kyushu University, \\ Fukuoka, Japan
}

\begin{abstract}
High purity metals with low melting temperatures such as indium (99.999\%), tin (99.9\%), lead (99\%), zinc (99.99\%) and aluminum (99.99\%) were processed using high-pressure torsion (HPT). An unusual softening behavior was observed in all these metals after processing by HPT at room temperature. Pure copper (99.99\%) and palladium $(99.95 \%)$ were used to simulate the softening behavior due to a thermal effect by processing and subsequently holding at the temperatures equivalent to room temperature of pure Al. It is shown that a hardness peak appears in any metal by static softening after processing by HPT at a homologous temperature of 0.32 which is equivalent to room temperature of pure Al. The contribution of dynamic softening on hardness decrease becomes more important as the homologous temperature and stacking fault energy increase. Microstructural examinations indicate that, although the stacking fault energy influences the rate of the microstructural evolution, the homologous temperature appears to be a dominant parameter to determine the steady-state grain size after processing by HPT.
\end{abstract}

Keywords: Hardness; Grain size; High-pressure torsion; Ultrafine-grained materials; Severe plastic deformation.

* Corresponding author.

Tel.: +8192802 2992; fax: +81928022992.

E-mail address: kaveh.edalati@zaiko6.zaiko.kyushu-u.ac.jp (K. Edalati). 


\section{Introduction}

Processing bulk metallic materials through the application of severe plastic deformation (SPD) leads to attainment of ultrafine-grained structures with a high hardness and strength [1-3]. Ighpressure torsion (HPT) is a typical process of SPD, where a thin disc or ring is placed between two massive anvils under a high pressure and intense shear strain is introduced by rotating the two anvils with respect to each other [4,5]. Application of HPT has shown that the microstructure as well as the hardness and strength evolve into a steady state with straining [6-18]. It has also been shown that the hardness after HPT processing is represented by a unique function of equivalent strain for various metals such as $\mathrm{Al}$ [5], $\mathrm{Mg}$ [19], $\mathrm{Cu}$ [20], $\mathrm{Fe}$ [21], $\mathrm{Ti}$ [22], $\mathrm{Zr}$ [23] and $\mathrm{Hf}$ [24].

The hardness-strain behavior of pure $\mathrm{Al}$ and $\mathrm{Mg}$ is different from other pure metals. In most metals, a steady level is reached directly following the initial increase with straining [5-24]. However, in pure $\mathrm{Al}$ with the purity level of $99.99 \%$ [5,25] and in pure $\mathrm{Mg}$ with the purity level of 99.9\% [19], the hardness initially increases with increasing strain and, after reaching a maximum, decreases to a constant level. This softening of high purity $\mathrm{Al}$ at large equivalent strains was observed in both monotonic and cyclic HPT [26,27] as well as in continuous HPT [28]. The mechanism for the unusual softening of pure $\mathrm{Al}$ at large strains was investigated in few papers. $\mathrm{Xu}$ et al. [25] attributed the softening to easy cross-slip and dynamic recovery due to large stacking fault energy (SFE) of Al. Edalati et al. [29] reported that a hardness peak appears in $\mathrm{Cu}$ at a homologous temperature of 0.32 in a similar way to $\mathrm{Al}$ because of a static recrystallization, and the hardness behavior in pure $\mathrm{Al}$ was attributed to its relatively high homologous temperature [17]. It is noted that both $\mathrm{Mg}$ and $\mathrm{Al}$ are similar in terms of SFE and the melting temperature. If the effect of SFE is dominant, a softening should be observed in pure metals with high SFE such as Pd and if the effect of homologous temperature is dominant a softening should be observed in pure metals with low melting temperatures such as $\mathrm{In}, \mathrm{Sn}, \mathrm{Pb}$ and $\mathrm{Zn}$. Therefore, the hardness behavior of these metals is examined in this paper, for the first time, after processing by HPT.

The grain size of pure $\mathrm{Al}$ and $\mathrm{Mg}$ at the steady-state is also different from that of other pure metals. In pure Al with the purity level of $99.99 \%$, the average grain size at the steady state was reported $1.2 \mu \mathrm{m}$ [14], $1.5 \mu \mathrm{m}$ [4], $1.9 \mu \mathrm{m}$ [17] and $2.1 \mu \mathrm{m}$ [16]. In pure Mg with the purity level of $99.9 \%$, the average grain size at the steady state was reported $1.0 \mu \mathrm{m}$ [19]. However, in other metals, the steady-state grain size is in the submicrometer level [7-24]. Although the larger grain size in Al is attributed to its high SFE [5,25] or to its low melting temperature [29], little is understood to date regarding the relation between the steady-state grain size and SFE or melting temperature of pure metals processed with HPT. Mohamed [30] investigated the correlations between the minimum grain size at the steady state and physical parameters for pure metals processed through ball milling using a dislocation model. However, this finding cannot be applied directly to HPT-processed pure metals because the mechanism of grain refinement is not the same for ball milling and HPT processing.

This study is thus initiated with the two objectives: first, to examine the possible softening behavior in HPT-processed pure metals such as $\mathrm{In}, \mathrm{Sn}, \mathrm{Pb}, \mathrm{Zn}, \mathrm{Al}, \mathrm{Cu}, \mathrm{Ni}$ and $\mathrm{Pd}$ and clarify the reason for the difference in the hardness behavior; and second, to investigate the effect of 
homologous temperature and SFE on the grain size at the steady state.

\section{Experimental materials and procedures}

High purity In (99.999\%), Sn (99.9\%), Pb (99\%), Ni (99.996\%) and $\mathrm{Pd}(99.95 \%)$ were received in a form of cold-rolled plates having dimensions of $1 \mathrm{~mm} \times 25 \mathrm{~mm} \times 50 \mathrm{~mm}$ for In, Sn and $\mathrm{Ni}, 1.5 \mathrm{~mm} \times 50 \mathrm{~mm} \times 100 \mathrm{~mm}$ for $\mathrm{Pb}$ and $0.3 \mathrm{~mm} \times 25 \mathrm{~mm} \times 30 \mathrm{~mm}$ for Pd. High purity $\mathrm{Zn}$ $(99.99 \%)$ was received in a form of ingot having dimensions of $20 \mathrm{~mm} \times 50 \mathrm{~mm} \times 120 \mathrm{~mm}$ and high purity $\mathrm{Al}(99.99 \%)$ and $\mathrm{Cu}(99.99 \%)$ were received in a form of cold-extruded rods with 10 $\mathrm{mm}$ diameter and $1250 \mathrm{~mm}$ length. Discs with $10 \mathrm{~mm}$ diameter and $0.8 \mathrm{~mm}$ thickness were prepared from the plates and rods using either of a wire-cutting electric discharge machine, a micro-cutter or scissors. For $\mathrm{In}, \mathrm{Sn}, \mathrm{Pb}, \mathrm{Zn}, \mathrm{Al}, \mathrm{Cu}$ and $\mathrm{Ni}$, the discs were ground to a thickness of $0.8 \mathrm{~mm}$. For $\mathrm{Pd}$, every three discs with $0.3 \mathrm{~mm}$ thickness were compressed together and the total thickness of $0.9 \mathrm{~mm}$ was reduced to $0.8 \mathrm{~mm}$. The discs with $0.8 \mathrm{~mm}$ thickness were annealed for 1 $\mathrm{h}$ at a temperature in the range of 0.6-0.92 $T_{m}$ ( $T_{m}$ : melting temperature) which is considered to be in the high temperature regime. The discs were annealed at $393 \mathrm{~K}$ for $\mathrm{In}, 453 \mathrm{~K}$ for Sn, $473 \mathrm{~K}$ for $\mathrm{Pb}, 523 \mathrm{~K}$ for $\mathrm{Zn}, 773 \mathrm{~K}$ for $\mathrm{Al}, 873 \mathrm{~K}$ for $\mathrm{Cu}, 973 \mathrm{~K}$ for $\mathrm{Ni}$ and $1273 \mathrm{~K}$ for $\mathrm{Pd}$ to give an initial grain size of $\sim 350 \mu \mathrm{m}$ for In, $\sim 590 \mu \mathrm{m}$ for $\mathrm{Sn}, \sim 160 \mu \mathrm{m}$ for $\mathrm{Pb}, \sim 1220 \mu \mathrm{m}$ for $\mathrm{Zn}, \sim 1050 \mu \mathrm{m}$ for $\mathrm{Al}$, $\sim 150 \mu \mathrm{m}$ for $\mathrm{Cu}$ and $\mathrm{Ni}$, and $\sim 50 \mu \mathrm{m}$ for Pd. The crystal structure of these elements, including their purity, melting temperature $T_{m}$, homologous temperature corresponding to room temperature 298/ $T_{m}$, and SFE, are given in Table 1 . The data in Table 1 were taken from Refs. [31-33].

Table 1. Purity, crystal structure, melting point $T_{m}$, homologous temperature corresponding to room temperature $298 / T_{m}$, and stacking fault energy SFE, for various elements.

\begin{tabular}{cccccc}
\hline Metal & $\begin{array}{c}\text { Purity } \\
(\%)\end{array}$ & Structure & $\begin{array}{c}\boldsymbol{T}_{\boldsymbol{m}} \\
(\mathrm{K})\end{array}$ & $\mathbf{2 9 8} / \boldsymbol{T}_{\boldsymbol{m}}$ & $\begin{array}{c}\text { SFE } \\
\left(\mathrm{mJ} . \mathrm{m}^{-2}\right)\end{array}$ \\
& & & {$[31]$} & & {$[32,33]$} \\
\hline In & 99.999 & Tetragonal & 429 & 0.69 & \\
$\mathbf{S n}$ & 99.9 & Tetragonal & 505 & 0.59 & \\
$\mathbf{P b}$ & 99 & fcc & 600 & 0.50 & 24.5 \\
$\mathbf{Z n}$ & 99.99 & hcp & 693 & 0.43 & 140 \\
$\mathbf{A l}$ & 99.99 & fcc & 933 & 0.32 & 166 \\
$\mathbf{C u}$ & 99.99 & fcc & 1357 & 0.22 & 45 \\
$\mathbf{N i}$ & 99.996 & fcc & 1728 & 0.17 & 125 \\
$\mathbf{P d}$ & 99.96 & fcc & 1825 & 0.16 & 180 \\
\hline
\end{tabular}

HPT was conducted at room temperature $(298 \mathrm{~K})$ using the $\mathrm{In}, \mathrm{Sn}, \mathrm{Pb}, \mathrm{Zn}$ and $\mathrm{Al}$ discs for either $N=0.25,1,2$ or 5 revolutions, at temperatures of $298 \mathrm{~K}, 373 \mathrm{~K}, 433 \mathrm{~K}, 473 \mathrm{~K}, 513 \mathrm{~K}, 543 \mathrm{~K}$ and $573 \mathrm{~K}$ using the $\mathrm{Cu}$ discs for $N=12$ revolutions, at temperatures of $298 \mathrm{~K}$ and $573 \mathrm{~K}$ using the 
$\mathrm{Pd}$ discs for 15 revolutions and at temperatures of $298 \mathrm{~K}$ using the Ni discs for 10 revolutions. A pressure of $P=1 \mathrm{GPa}$ was applied on $\mathrm{In}, \mathrm{Sn}, \mathrm{Pb}$ and $\mathrm{Al}$ discs and a pressure of $P=2 \mathrm{GPa}$ was applied on $\mathrm{Zn}, \mathrm{Cu}, \mathrm{Ni}$ and $\mathrm{Pd}$ discs, while rotating with a speed of $\omega=0.5 \mathrm{rpm}$. The details concerning the HPT anvils were reported elsewhere [23]. The $\mathrm{Cu}$ and $\mathrm{Pd}$ discs, after processing with HPT at elevated temperatures, were held at the same temperature as the HPT processing temperature for a period of $30 \mathrm{~h}$, as described in an earlier paper [29].

Following HPT and after keeping the samples for duration time of $30 \mathrm{~h}$, the discs were subjected to Vickers microhardness measurement and evaluated using optical microscopy (OM), electron back-scatter diffraction (EBSD) analysis and transmission electron microscopy (TEM).

First, the HPT-processed discs including the annealed discs were polished to mirror-like surfaces and the Vickers microhardness was measured at selected points from the center to periphery, using the procedure described earlier [20]. The microhardness was measured with an applied load of $10 \mathrm{~g}$ on $\mathrm{In}, \mathrm{Sn}$ and $\mathrm{Pb}$ discs, of $50 \mathrm{~g}$ on $\mathrm{Zn}$ and $\mathrm{Al}$ discs and of $200 \mathrm{~g}$ on $\mathrm{Cu}, \mathrm{Ni}$ and $\mathrm{Pd}$ discs for duration time of $15 \mathrm{~s}$. The equivalent strain, $\varepsilon$, at each hardness measurement was calculated as [7]:

$$
\varepsilon=\frac{2 \pi r N}{\sqrt{3} t}
$$

where $r$ is the distance from the disc center, $N$ is the number of revolutions and $t$ is the thickness of disc. The thickness reduction during HPT processing and the slippage between the anvils and sample were ignored in the calculation of the equivalent strain in this study $[21,34]$.

Second, for OM observations, the In, $\mathrm{Sn}$ and $\mathrm{Pb}$ discs were polished to mirror-like surfaces and the In discs were electro-etched in a solution of $5 \% \mathrm{HF}$ and $95 \% \mathrm{H}_{2} \mathrm{O}$ at $298 \mathrm{~K}$ under an applied voltage of $15 \mathrm{~V}$; the $\mathrm{Sn}$ discs were etched in a solution of either $5 \% \mathrm{HCl}$ and $95 \% \mathrm{CH}_{3} \mathrm{OH}$ or $5 \%$ $\mathrm{HNO}_{3}$ and $95 \% \mathrm{C}_{2} \mathrm{H}_{5} \mathrm{OH}$ at $298 \mathrm{~K}$; and the $\mathrm{Pb}$ discs were etched in a solution of $5 \% \mathrm{HNO}_{3}$ and $95 \% \mathrm{C}_{2} \mathrm{H}_{5} \mathrm{OH}$ at $298 \mathrm{~K}$ or electro-etched using a solution of $30 \% \mathrm{HClO}_{4}$ and $70 \% \mathrm{CH}_{3} \mathrm{COOH}$ at $298 \mathrm{~K}$ under an applied voltage of $5 \mathrm{~V}$. The etched samples were observed using OM for microstructural observation.

Third, for EBSD analysis, the $\mathrm{Zn}, \mathrm{Al}, \mathrm{Cu}$ and $\mathrm{Pd}$ discs were polished to mirror-like surfaces and further subjected to electro-chemical polishing in a solution of $50 \% \mathrm{HClO}_{4}$ and $50 \% \mathrm{C}_{2} \mathrm{H}_{5} \mathrm{OH}$ at $298 \mathrm{~K}$ under an applied voltage of $5 \mathrm{~V}$ for $\mathrm{Zn} ; 15 \% \mathrm{HClO}_{4}, 15 \% \mathrm{C}_{3} \mathrm{H}_{5}(\mathrm{OH})_{3}$ and $70 \% \mathrm{CH}_{3} \mathrm{OH}$ at $263 \mathrm{~K}$ under an applied voltage of $13 \mathrm{~V}$ for $\mathrm{Al} ; 15 \% \mathrm{HNO}_{3}, 15 \% \mathrm{C}_{3} \mathrm{H}_{5}(\mathrm{OH})_{3}$ and $70 \% \mathrm{CH}_{3} \mathrm{OH}$ at $263 \mathrm{~K}$ under an applied voltage of $9 \mathrm{~V}$ for $\mathrm{Cu}$; and $50 \% \mathrm{HCl}, 20 \% \mathrm{C}_{3} \mathrm{H}_{5}(\mathrm{OH})_{3}$ and $30 \% \mathrm{C}_{2} \mathrm{H}_{5} \mathrm{OH}$ at $298 \mathrm{~K}$ under an applied voltage of $20 \mathrm{~V}$ for Pd. EBSD analysis was performed at a voltage of $20 \mathrm{kV}$ and the crystal orientations were determined using an automatic beam scanning system. The EBSD probe size for $\mathrm{Zn}, \mathrm{Al}, \mathrm{Cu}$ and $\mathrm{Pd}$ was $150 \mathrm{~nm}, 100 \mathrm{~nm}, 90 \mathrm{~nm}$ and $70 \mathrm{~nm}$, respectively.

Fourth, for TEM, discs with $3 \mathrm{~mm}$ in diameter were punched from the $\mathrm{Al}, \mathrm{Cu}, \mathrm{Ni}$ and $\mathrm{Pd}$ discs at $3.5 \mathrm{~mm}$ away from the center. The $3 \mathrm{~mm}$ discs were ground to a thickness of $0.15 \mathrm{~mm}$ and further thinned for transmission electron microscopy (TEM) with a twin-jet electro-chemical polisher using the solutions as mentioned above for $\mathrm{Al}, \mathrm{Cu}$ and $\mathrm{Pd}$. Thin specimens for $\mathrm{Ni}$ were made in the same way using a solution of $10 \% \mathrm{HSO}_{4}, 10 \% \mathrm{HNO}_{3}$ and $80 \% \mathrm{CH}_{3} \mathrm{OH}$ at $263 \mathrm{~K}$ under an applied voltage 
of $20 \mathrm{~V}$. TEM was performed at a voltage of $200 \mathrm{kV}$ for microstructural observation and for recording selected-area electron diffraction (SAED) patterns.

The average size of grains separated by large misorientation angles was determined by either OM, EBSD or TEM observations. For, OM and EBSD, the average grain sizes were determined by the linear intercept method. For TEM, the grain size values were obtained by measuring the two orthogonal axes of the bright areas in the dark field images. More than 50 grains were calculated for each group of samples. The low-angle grain boundaries were excluded in the measurements and the twin boundaries which were present in some elements were considered as grain boundaries.

\section{Results}

The hardness values measured at room temperature $\left(0.32 T_{m}\right)$ are plotted against the equivalent strain in Fig. 1 for Al. Data points fall well on a single curve in consistence with earlier studies [5,6,26-29]. The hardness of Al initially increases to a maximum, decreases with a further increase in the equivalent strain and reaches a steady state level where the hardness remains unchanged with straining. Despite the fact that the equivalent strain is theoretically zero at the center of disc according to Eq. (1), close inspection of Fig. 1 reveals that the hardness at the disc center increases with increasing the number of revolutions. This is due to two reasons [21]: first, in practice, hardness measurement at the exact center is difficult but the hardness values were measured within a circular area with $0.2 \mathrm{~mm}$ in diameter; second, a small misalignment of the rotation axes between the lower and upper anvils may result in imposing an additional shear strain to the center of the disc, although the alignment was adjusted well within $\pm 0.01 \mathrm{~mm}$ in this study. Microstructures at the steady states are shown in Fig. 2 for Al, where (a) is a TEM bright-field image and (b) is an orientation map obtained by EBSD. Few dislocations are visible and grain boundaries are straight and well defined with a grain size of $\sim 1.9 \mu \mathrm{m}$. These microstructural features are also consistent with earlier observations for HPT-processed samples [5,6,29]. However, the average grain size is higher than the grain size of $\sim 1.2 \mu \mathrm{m}$ reported for samples processed with equal-channel angular pressing $[35,36]$.

The hardness is plotted against the equivalent strain in Fig. 3 for $\mathrm{Zn}$ processed at room temperature $\left(0.43 T_{m}\right)$. As in $\mathrm{Al}$, the hardness of $\mathrm{Zn}$ initially increases and after reaching a maximum decreases to a steady state level. Orientation map analysis using EBSD is shown in Fig. 4 for the sample processed for $N=1$ revolution at three representative strained conditions. Here, (a) corresponds to the center of disc, $\varepsilon=0$, where the hardness increases; (b) corresponds to $1 \mathrm{~mm}$ away from the disc center, $\varepsilon=4$, where the hardness takes the maximum; (c) corresponds to $3 \mathrm{~mm}$ away from the disc center, $\varepsilon=13$, where the hardness reaches a steady state. It is apparent from Fig. 4(a) that at $\varepsilon=0$, the microstructure consists of large grains. In Fig. 4(b) where $\varepsilon=4$, the grains become smaller and low quality of image indicates that the lattice strain should be high. In Fig. 4(c) where $\varepsilon=13$, small grains with straight and well-defined grain boundaries appear and the grains size reaches $\sim 5.2 \mu \mathrm{m}$. These microstructural features of $\mathrm{Zn}$ at different strained conditions are similar to the earlier observation of $\mathrm{Al} \mathrm{[6]} \mathrm{and} \mathrm{Mg}$ [19] and different from those of $\mathrm{Cu}$ [9] and $\mathrm{Fe}$ [10]. 


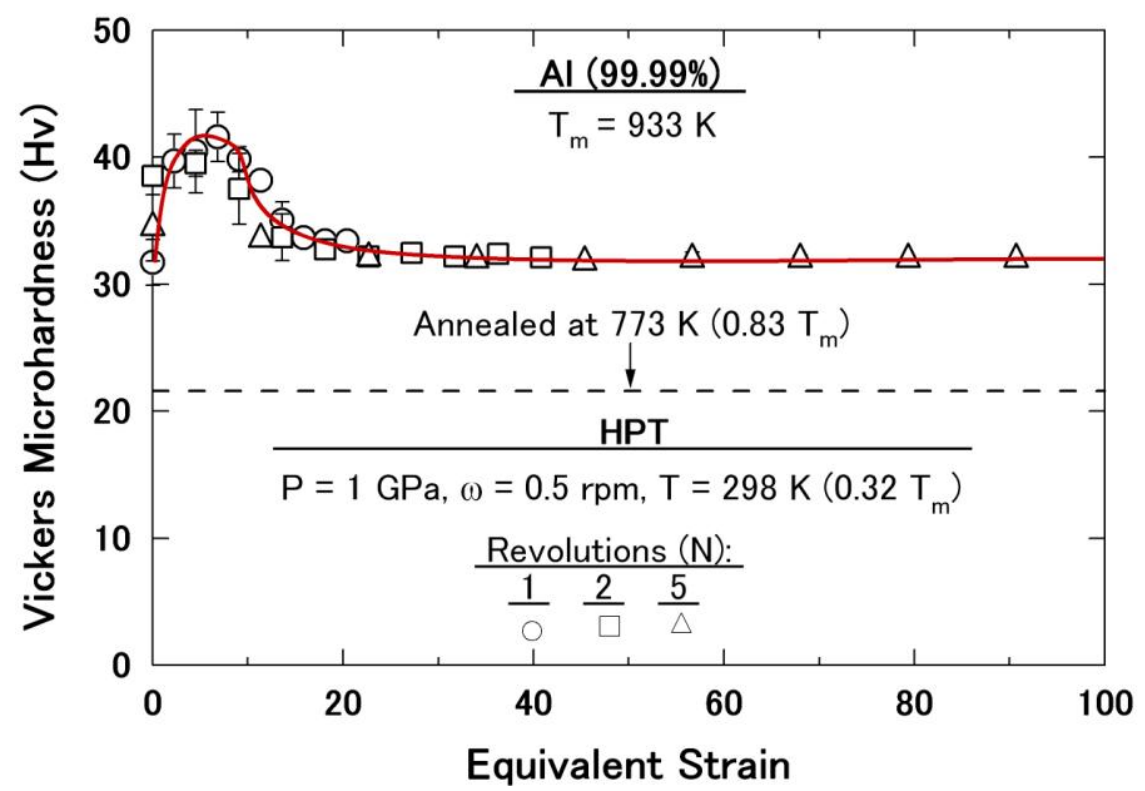

Fig. 1. Vickers microhardness plotted against equivalent strain for $\mathrm{Al}$ after HPT at room temperature.
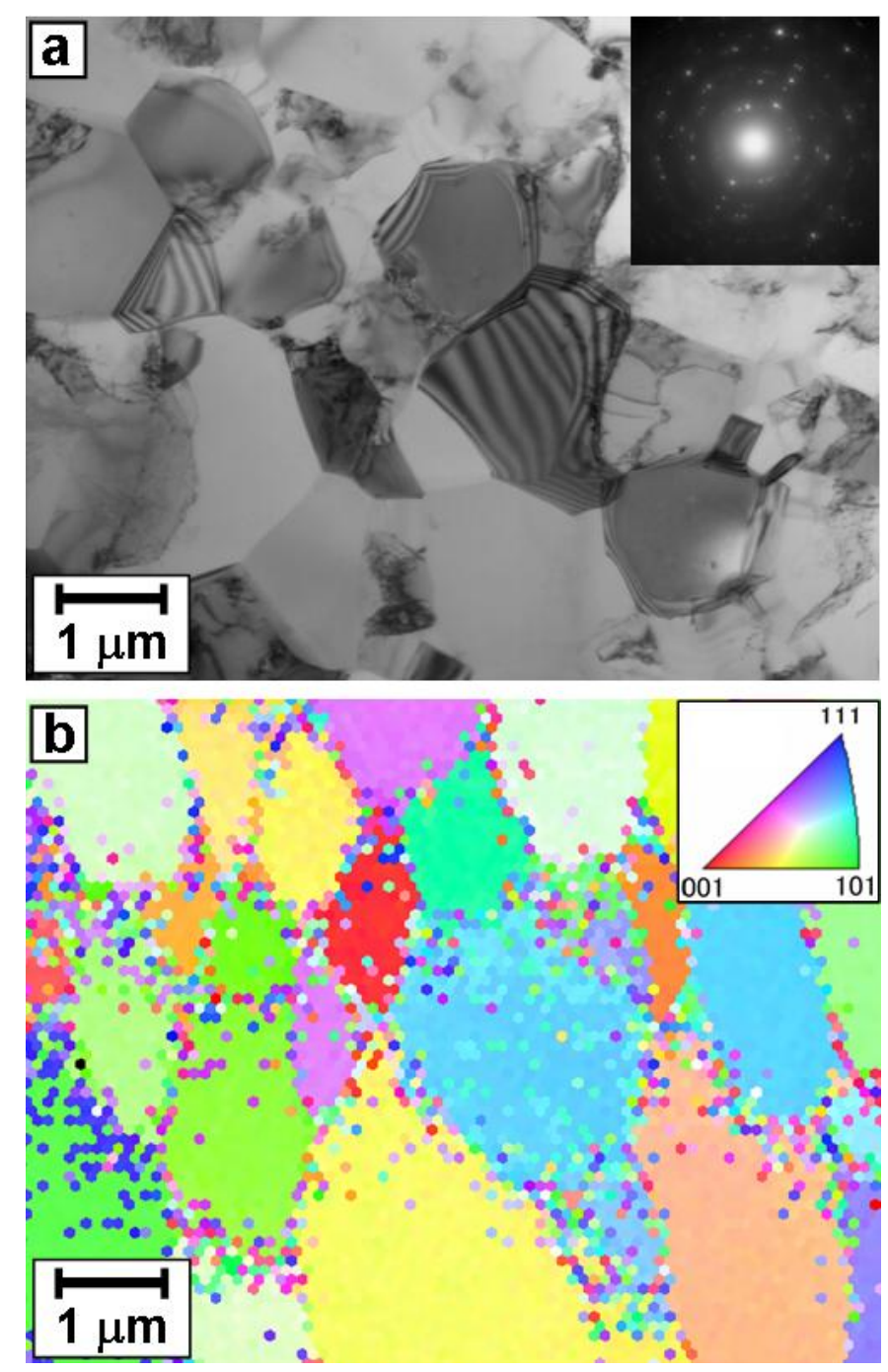

Fig. 2. (a) TEM bright-field image and SAED patterns and (b) EBSD orientation map for Al after HPT for 5 revolutions at room temperature. 


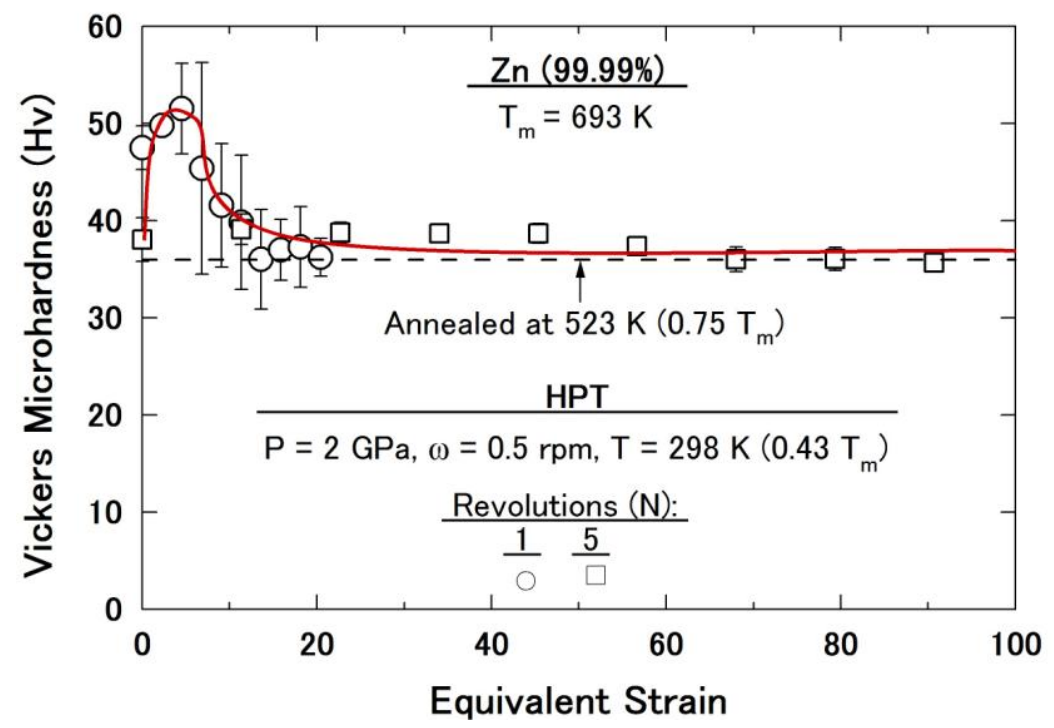

Fig. 3. Vickers microhardness plotted against equivalent strain for $\mathrm{Zn}$ after HPT at room temperature.
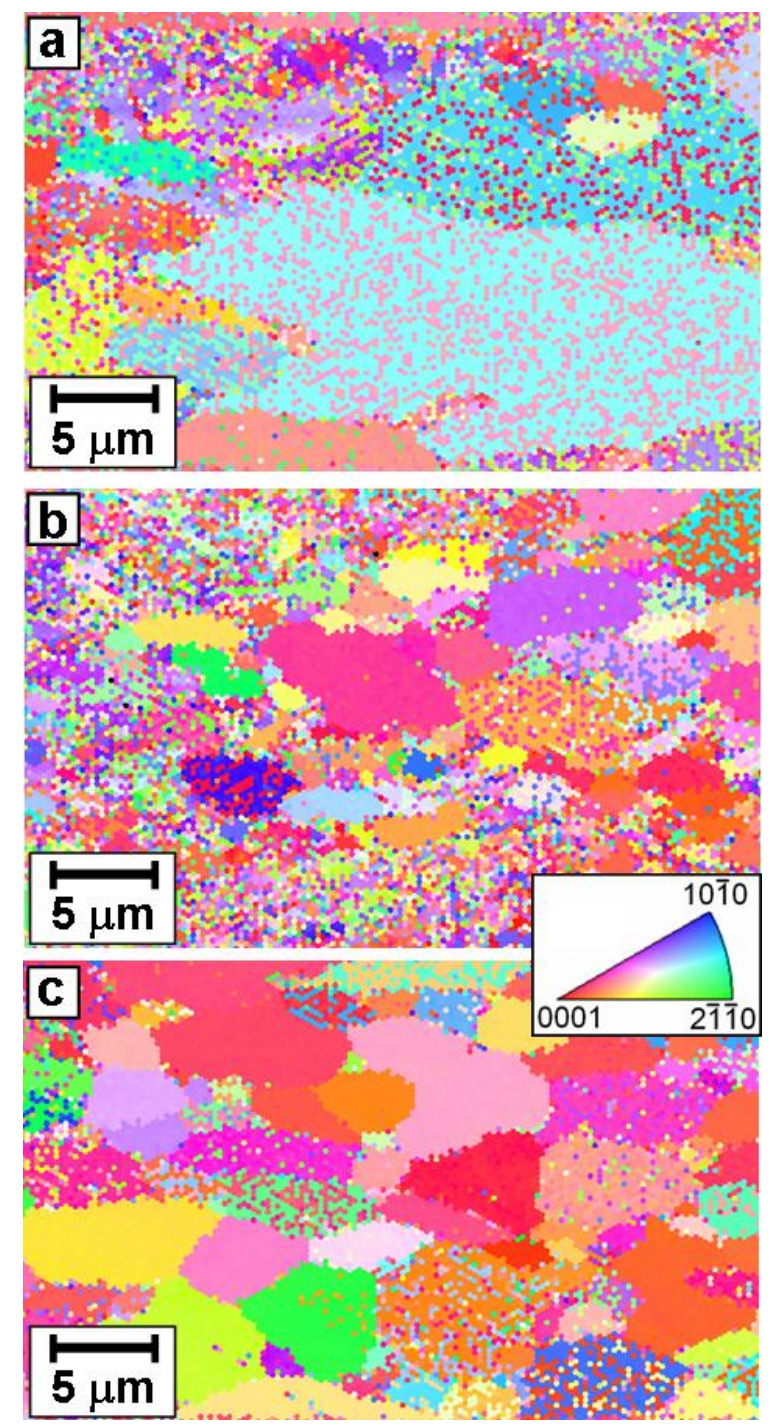

Fig. 4. EBSD orientation map for Zn after HPT for 1 revolution at room temperature at (a) disc center, (b) $1 \mathrm{~mm}$ from center and (c) $3 \mathrm{~mm}$ from center. 
The hardness is plotted against the equivalent strain in Fig. 5 for (a) $\mathrm{Pb}$, (b) $\mathrm{Sn}$ and (c) In processed at room temperature (0.43, 0.59 and $0.69 T_{m}$ for $\mathrm{Pb}, \mathrm{Sn}$ and $\mathrm{In}$, respectively). There are two points to be noted regarding the plots in Fig. 5. First, although the hardness behavior is similar to $\mathrm{Al}$ and $\mathrm{Zn}$ and the average hardness is higher in the strain range of $\varepsilon<20$ than that of $\varepsilon>20$, the hardness variation with straining is insignificant in these three metals. Second, the hardness values measured after processing at room temperature are unusually lower than those annealed at elevated temperatures prior to HPT processing. For Al, as shown in Fig. 1, the hardness level at the steady state is higher than that of the annealed sample and, for $\mathrm{Zn}$, it is almost the same as the hardness level of the annealed sample as shown in Fig. 3.
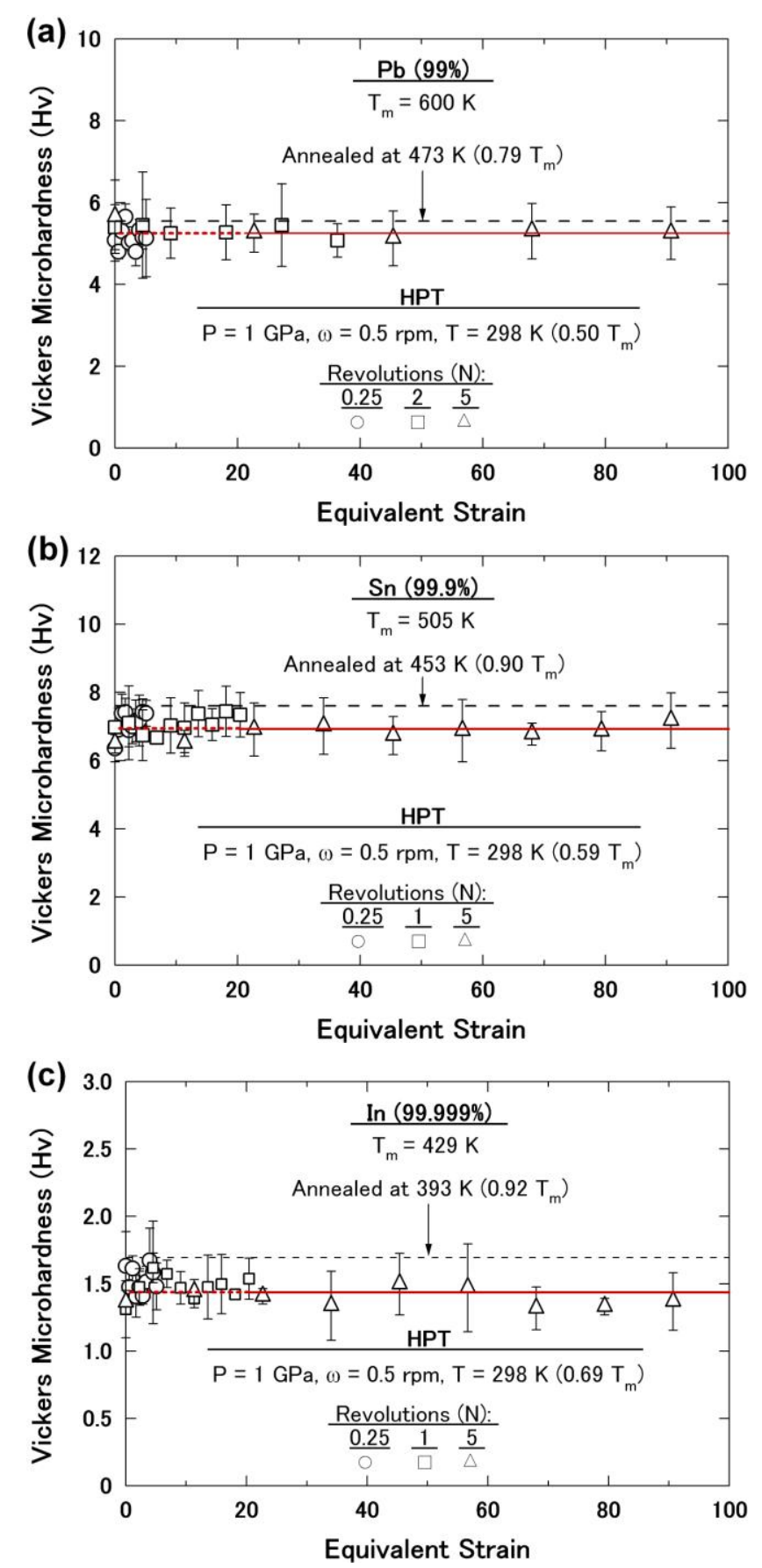

Fig. 5. Vickers microhardness plotted against equivalent strain for (a) $\mathrm{Pb}$, (b) Sn and (c) In after HPT at room temperature. 
OM Micrographs are shown in Fig. 6 for (a, b) Pb, (c, d) Sn and (e, f) In, where (a), (c) and (e) were taken from the annealed samples and (b), (d) and (f) were taken from the samples subjected to HPT at room temperature for $N=5$ revolutions at $3.5 \mathrm{~mm}$ away from the disc center. It is shown that the microstructures consist of large grains and, whereas some twins are visible in $\mathrm{Pb}$ and $\mathrm{In}$, they are rarely seen in $\mathrm{Sn}$. The average grain sizes of $\mathrm{Pb}, \mathrm{Sn}$ and $\mathrm{In}$ appear to be $\sim 160, \sim 590$ and $\sim 350 \mu \mathrm{m}$ after annealing and they are compared with $\sim 100, \sim 135$ and $\sim 320 \mu \mathrm{m}$ after processing by HPT, respectively. These grain sizes at the steady state are much higher than any other reported sizes for SPD-processed materials [1-29]. It is noted that despite a moderate decrease in the grain size after the HPT processing, the hardness decreases slightly by HPT.
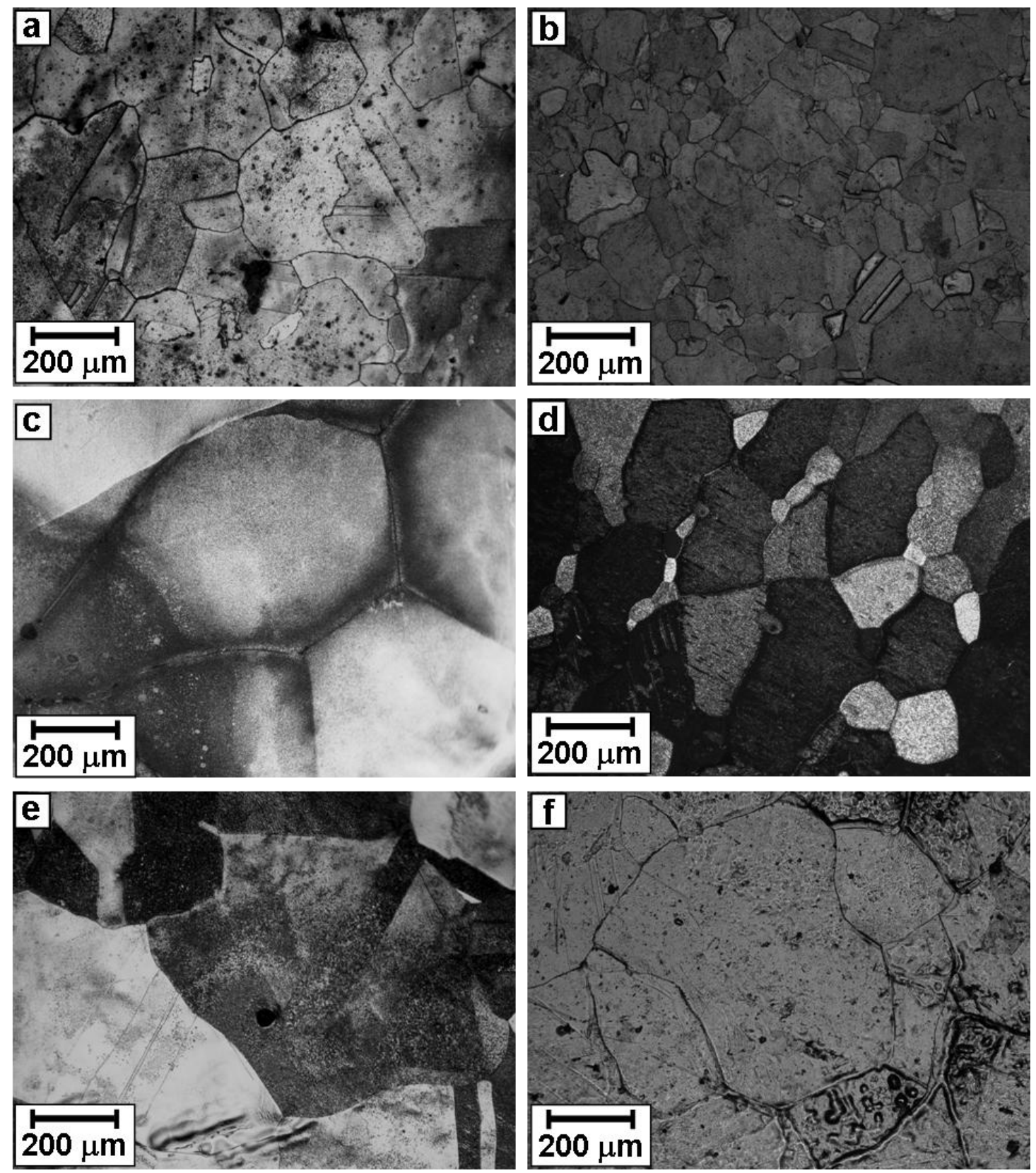

Fig. 6. Micrographs of (a, b) Pb, (c, d) Sn and (e, f) In observed using optical microscopy, where (a), (c) and (e) are after annealing for $1 \mathrm{~h}$ and (b), (d) and (f) are after HPT for 5 revolutions at room temperature. 


\section{Discussion}

Because significant numbers of dislocations are generated as a consequence of intense straining through HPT processing, it is reasonable to consider that the difference in the hardness variation and microstructural feature arises from the difference in dislocation behavior between the metals. It is most probable that four important factors affect the dislocation behavior in pure metals: they are first the purity level, second the crystal structure, third the homologous temperature, and forth the SFE. The purity level is an important factor affecting the dislocation mobility, but this effect can be the same for all elements adopted in this study and in the earlier studies of $\mathrm{Mg}$ [19], $\mathrm{Cu}$ [20], Fe [21], Ti [22], Zr [23] and Hf [24], because all these selected metals have almost the same purity level. Since the softening behavior is observed for different crystal structures such as tetragonal (In, Sn), fcc (Al, $\mathrm{Cu}, \mathrm{Pd})$ and hcp $(\mathrm{Mg}, \mathrm{Zn})$, the behavior must be common to any crystal structures. This study thus examines possible effects of the two other factors, the homologous temperature and the SFE, on the hardness behavior and the grain size after HPT.

\subsection{Effect of homologous temperature on hardness behavior}

Although HPT was conducted at room temperature $(298 \mathrm{~K})$ for all selected metals in this paper such as $\mathrm{In}, \mathrm{Sn}, \mathrm{Pb}, \mathrm{Zn}$ and $\mathrm{Al}$ as well as for the metals studied in the earlier papers such as $\mathrm{Mg}$ [19], $\mathrm{Cu}$ [20], Fe [21], Ti [22], Zr [23] and Hf [24], the temperature of $298 \mathrm{~K}$ corresponds to different homologous temperatures varied from 0.12 for $\mathrm{Hf}$ [24] to 0.69 for In. Thus, the dislocation mobility including the behavior of recovery and recrystallization should be different between the individual metals. Here, the pure $\mathrm{Cu}$ was processed at a selected temperature in the range of 298-573 K $\left(0.22-0.42 T_{m}\right)$ to simulate a thermal effect on the hardness behavior in pure metals. Furthermore, it is important to consider that the discs subjected to HPT at room temperature are kept for some periods of time before hardness measurement and microstructural observation. Therefore, the HPT-processed $\mathrm{Cu}$ discs at elevated temperatures were kept at the same corresponding temperatures for $30 \mathrm{~h}$.

Fig. 7(a) plots the hardness variation with the equivalent strain for $\mathrm{Cu}$ discs processed for $N=$ 12 revolutions at different temperatures. The hardness variations at elevated temperatures are essentially the same as the one at room temperature as reported in an earlier paper [20] and no hardness peak is observed at the selected temperatures. Now the major difference is that the steady state level decreases with an increase in the processing temperature. Thus, this indicates unambiguously that dynamic softening (due to recovery and/or recrystallization) occurs during HPT. In order to simulate the static softening after processing by HPT, the HPT-processed Cu discs at elevated temperatures were annealed at the same corresponding temperatures for $30 \mathrm{~h}$. The hardness values are then plotted against the equivalent strain in Fig. 7(b) for different processing temperatures. It is now apparent that a hardness maximum appears at homologous temperatures higher than 0.27 and such a maximum is shifted to lower equivalent strain as the homologous temperature increases. Furthermore, the hardness level at the steady state is decreased with the post-HPT annealing. In accordance with an earlier study [29], the hardness peak appears by static softening after processing by HPT in $\mathrm{Cu}$. 

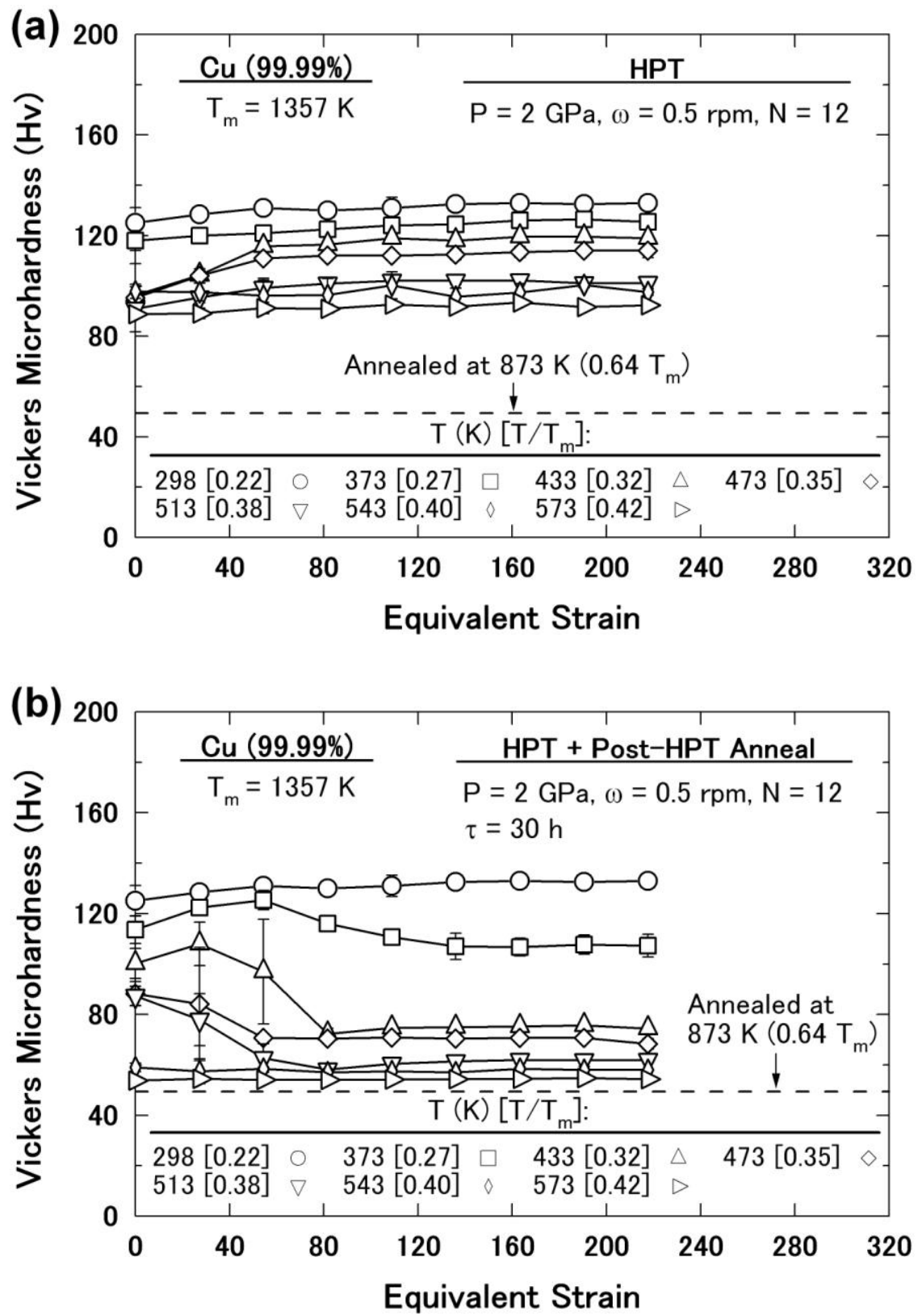

Fig. 7. Vickers microhardness plotted against equivalent strain for $\mathrm{Cu}$ after (a) HPT at various temperatures for 12 revolutions and (b) post-HPT annealing at the same corresponding temperature to HPT for $30 \mathrm{~h}$.

The contribution of dynamic softening to the hardness decrease at a temperature of $\mathrm{T}$ with respect to room temperature, $R_{D}$, may be estimated as

$$
R_{D}=\frac{H V_{R T}-H V_{T}}{H V_{R T}-H V_{P A}} \times 100
$$

where $H V_{R T}$ is the hardness after processing by HPT at room temperature, $H V_{T}$ is the hardness after processing by HPT at a temperature of $T$ and $H V_{P A}$ is the hardness after post-HPT annealing at a temperature of $T$. Considering the hardness values at the steady states in Fig. 7(a) and (b), $R_{D}$ values are then estimated and plotted against the homologous temperature in Fig. 8. This plot indicates that the contribution of dynamic softening to the hardness decrease becomes more important as the 
homologous temperature increases. Therefore, the dynamic softening is expected to be the dominant mechanism for the softening behavior in low-melting metals such as $\mathrm{Pb}$, Sn and In. Extrapolating the data points for $\mathrm{Cu}$ in Fig. 8 to an homologous temperature of 0.5 results in $R_{D}=70 \%$.

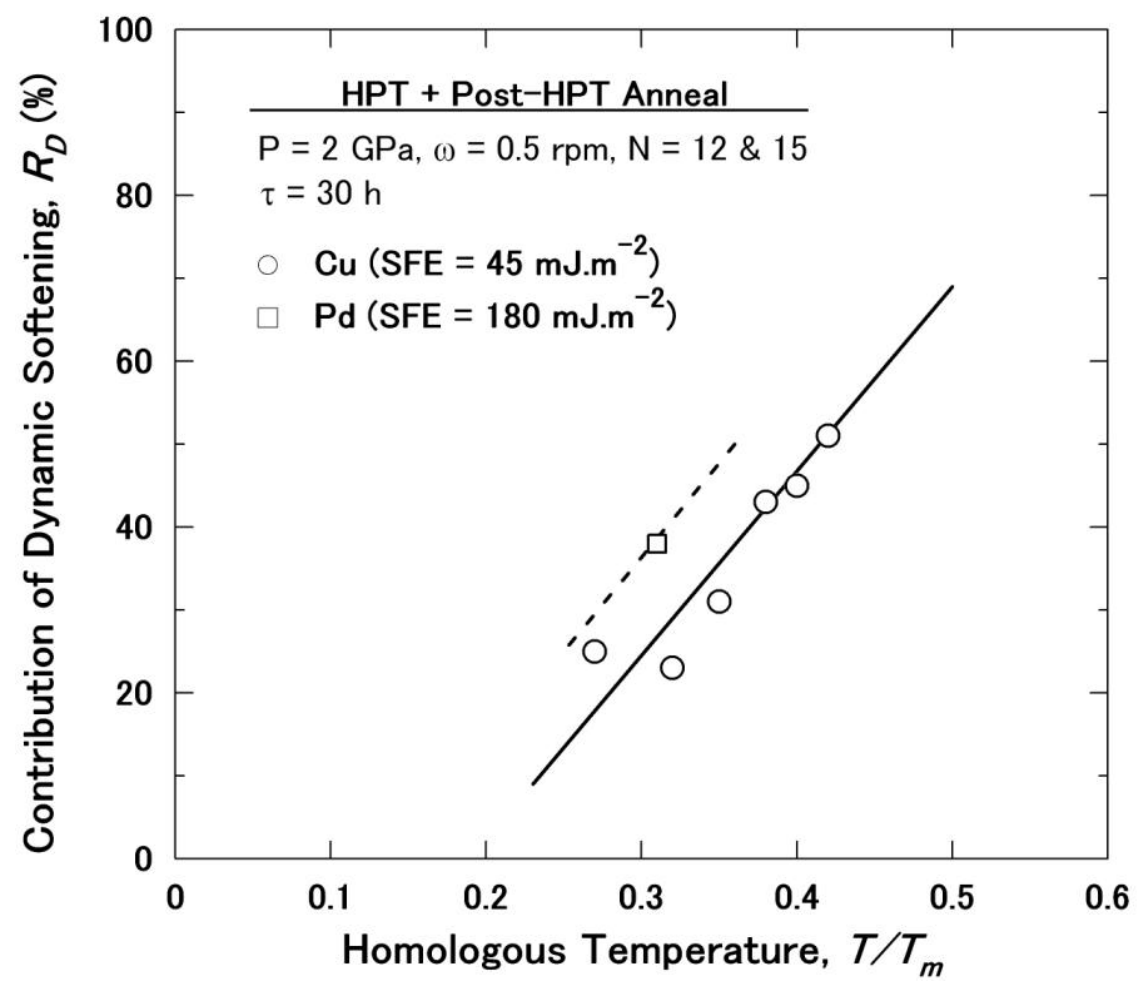

Fig. 8. Contribution of dynamic softening, $R_{D}$, plotted against homologous temperature, $T / T_{m}$, for $\mathrm{Cu}$ and $\mathrm{Pd}$.

Microstructures including SAED patterns are shown in Fig. 9 for $\mathrm{Cu}$ after HPT processing at $433 \mathrm{~K}$ for $(\mathrm{a}, \mathrm{b}) N=1$, (c, d) $N=4$ and (e, f) $N=12$ revolutions and post-HPT annealing at $433 \mathrm{~K}$ for 30 h. Panels (a), (c) and (e) in Fig. 9 are TEM bright-field images, panels (b) and (d) in Fig. 9 are TEM dark-field images taken with the diffracted beams indicated by an arrow in the SAED patterns and (f) is an orientation map by EBSD. The temperature of $433 \mathrm{~K}$ was selected because it is $0.32 T_{m}$ for $\mathrm{Cu}$ and is equivalent to the room temperature for Al. It is noted that $N=1$ revolution corresponds to $\varepsilon=16$ where the hardness increases, $N=4$ to $\varepsilon=60$ where the hardness takes the maximum, and $N=12$ to $\varepsilon=190$ where the hardness reaches a steady state. Many dislocations are visible within grains in Fig. 9(a)-(d), and grain boundaries are ill-defined. The grain size is fairly reduced to $2.9 \mu \mathrm{m}$ in Fig. 9(e) and (f). The microstructure at the steady state contains few dislocations as shown in Fig. 9(e) and many twins are visible in the grains. These are typical features observed after annealing of deformed fcc metals with low SFE. These microstructural features of $\mathrm{Cu}$ at different strained conditions are similar to those of $\mathrm{Zn}$ as shown in Fig. 4 as well as to the earlier observation of $\mathrm{Al}$ [6] and $\mathrm{Mg}$ [19]. All these results suggest the importance of homologous temperature in softening behavior of pure metals. 

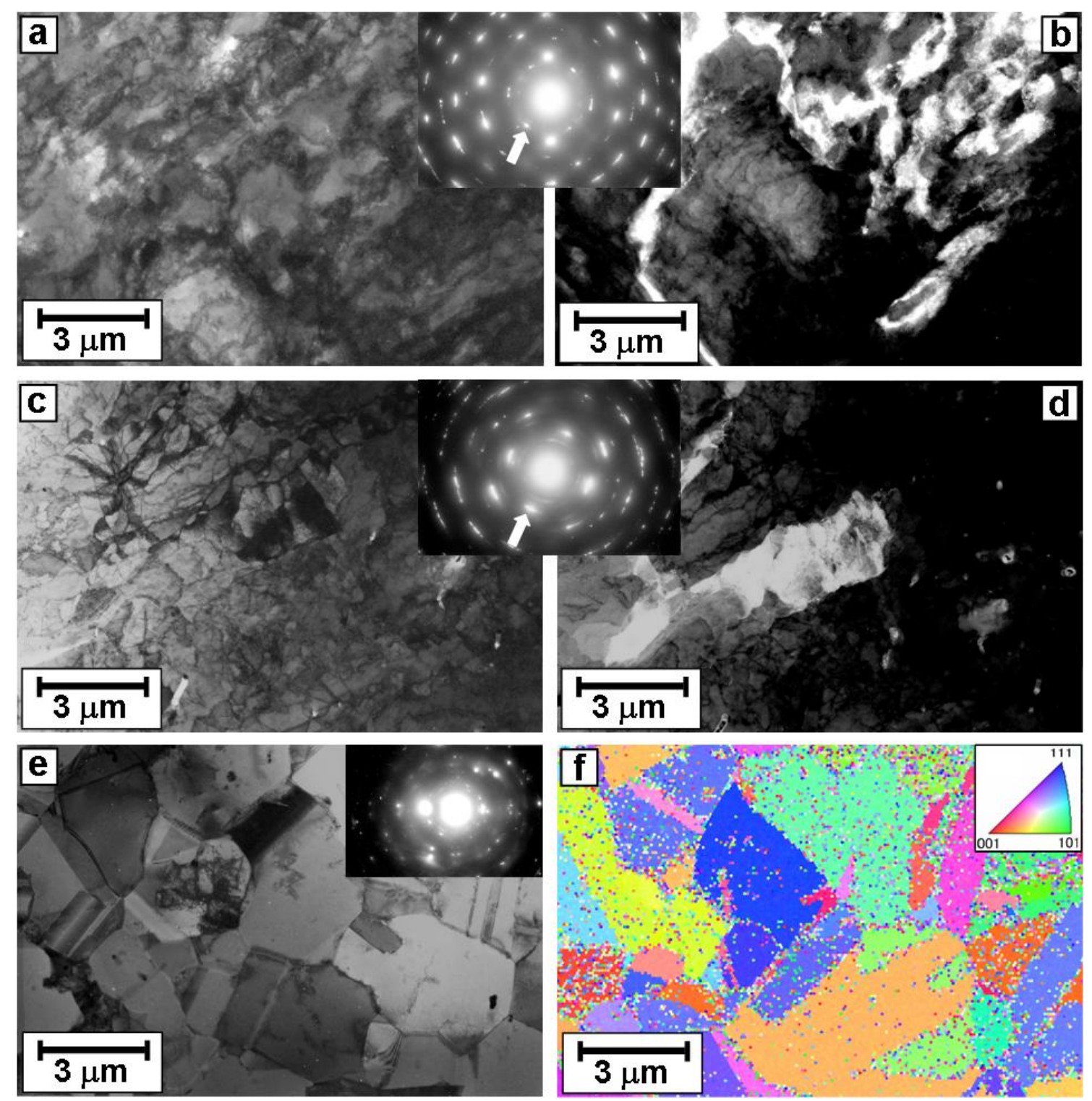

Fig. 9. (a)-(e) TEM micrographs and SAED patterns and (f) EBSD orientation map for $\mathrm{Cu}$ after HPT processing at $433 \mathrm{~K}$ for $(\mathrm{a}, \mathrm{b}) \mathrm{1}$, (c, d) 4 and (e, f) 12 revolutions and post-HPT annealing at $433 \mathrm{~K}$ for $30 \mathrm{~h}$, where (b) and (d) are dark-field images of (a) and (c), respectively, taken with the diffracted beams indicated by arrows in SAED pattern.

\subsection{Effect of stacking fault energy on hardness behavior}

It is thus clearly demonstrated that static recrystallization occurs after HPT processing of $\mathrm{Cu}$ when the temperature for HPT and subsequent holding of the sample becomes equivalent to the room temperature as in $\mathrm{Al}$ and $\mathrm{Mg}\left(T=0.32 T_{m}\right)$ and $\mathrm{Zn}\left(T=0.42 T_{m}\right)$. The results of $\mathrm{Cu}$ are then well consistent with those of $\mathrm{Al}, \mathrm{Mg}$ and $\mathrm{Zn}$. However, it is important to examine the effect of SFE on the hardness behavior and microstructural feature along with HPT operation because, as given in Table 1, the SFE is large as $166 \mathrm{~mJ} \mathrm{~m}^{-2}$ for $\mathrm{Al}, 125 \mathrm{~mJ} \mathrm{~m}^{-2}$ for $\mathrm{Mg}$ and $140 \mathrm{~mJ} \mathrm{~m}^{-2}$ for $\mathrm{Zn}$, but is small as $45 \mathrm{~mJ} \mathrm{~m}^{-2}$ for $\mathrm{Cu}$ [32]. It is well known that the dislocation mobility is assisted with two main mechanisms: cross-slip and climb. The controlling factor for cross-slip is SFE as well as 
homologous temperature and the controlling factor for climb is lattice self-diffusion and homologous temperature. In contrast to cubic metals, the cross-slip is very difficult to occur in hcp metals because of crystallographic anisotropy and limited slip systems. Therefore, the climb should be the main mechanism for softening of strain-hardened hcp Zn, which is mainly controlled by the homologous temperature. However, in fcc metals, it is well established that the distance between the two dissociated partial dislocations is small when SFE (SFE/Gb, where $G$ is the shear modulus and $b$ is the Burger vector) is large and the smaller distance promotes the dislocation mobility through cross-slip mechanism as for the case of Al. The reverse is applicable so that the dislocation mobility is low when SFE is small as in $\mathrm{Cu}$. Consequently, the microstructure evolves much faster in $\mathrm{Al}$ when compared to $\mathrm{Cu}$. Therefore, the softening may even proceed dynamically during HPT as suggested by $\mathrm{Xu}$ et al. [25].

In order to clarify the effect of SFE on softening behavior, pure Pd was used to simulate a thermal effect on the hardness behavior and microstructural evolution of pure Al. As given in Table 1 , the SFE is $180 \mathrm{~mJ} \mathrm{~m}^{-2}$ for Pd which is close to $166 \mathrm{~mJ} \mathrm{~m}^{-2}$ for $\mathrm{Al}$ [32]. As attempted in the $\mathrm{Cu}$ case, this simulation consists of processing and subsequently holding the pure $\mathrm{Pd}$ at $573 \mathrm{~K}\left(0.31 T_{m}\right)$, which is equivalent to room temperature for pure Al.

Fig. 10(a) plots the hardness variation with the equivalent strain for Pd discs processed at the temperatures of $273 \mathrm{~K}\left(0.16 T_{m}\right)$ and $573 \mathrm{~K}\left(0.31 T_{m}\right)$ for $N=15$ revolutions. Despite the high SFE for $\mathrm{Pd}$, the hardness variations are essentially the same as pure $\mathrm{Cu}$ and no maximum appears in the plots of both temperatures. The differences are that the steady state level decreases with increasing temperature because of a dynamic softening. In order to simulate the effect of static softening, the HPT-processed Pd disc at $573 \mathrm{~K}$ was held at the same corresponding temperature for $30 \mathrm{~h}$. The hardness values are then plotted against the equivalent strain in Fig. 10(b). It is now apparent that a hardness maximum appears and the hardness level decreases due to a static softening. An orientation map by EBSD is shown in Fig. 11 for the steady state condition after annealing at $573 \mathrm{~K}$ for $30 \mathrm{~h}$. The grain boundaries are smooth and straight, the grains are slightly elongated and the average grain size obtained by measuring the two orthogonal axes of the grains is $\sim 1.4 \mu \mathrm{m}$. The feature appears to be typical of grains after annealing. A comparison of Figs. 2 and 11 indicates that the microstructures of $\mathrm{Al}$ and $\mathrm{Pd}$ are very similar at the homologous temperature of 0.32 . The difference may be that whereas some elongated grains are observed in Pd as shown in Fig. 11, they are rarely seen in $\mathrm{Al}$ as in Fig. 2.

Therefore, the peak appearance for pure Al with straining by HPT must be due to static softening. However, the hardness decrease should be due to both dynamic and static softening. Inspection of Fig. 10(a) and (b) shows that the contribution of dynamic softening to the total softening using Eq. (2) is $R_{D}=38 \%$ for the Pd processed at $0.31 T_{m}$. This $R_{D}$ value for Pd is also included in Fig. 8. For comparison, the $R_{D}$ value for $\mathrm{Cu}$ at the same homologous temperature is estimated to be $23 \%$. This comparison indicates that the contribution of dynamic softening on the hardness decrease becomes more important as the SFE increases because the SFE is $45 \mathrm{~mJ} . \mathrm{m}^{-2}$ for $\mathrm{Cu}$ and $180 \mathrm{~mJ} . \mathrm{m}^{-2}$ for Pd [32]. It should be noted that neither the hardness peak nor the hardness decrease was observed in low purity Al (99.7\%) [8]. The presence of impurity elements then 
suppresses the recovery and recrystallization, stabilizes the microstructure and eliminates the softening after processing by HPT [37].
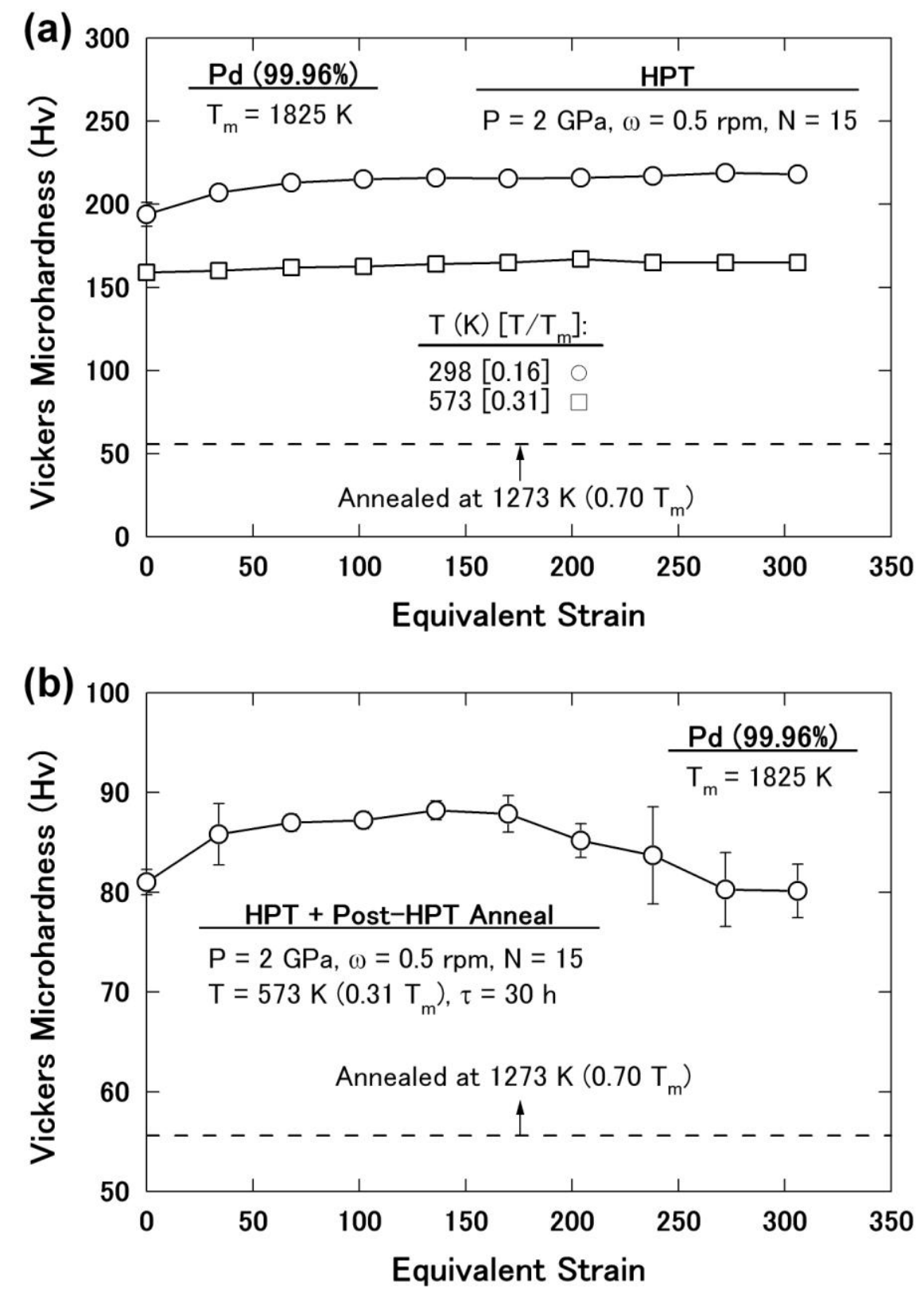

Fig. 10. Vickers microhardness plotted against equivalent strain for Pd after (a) HPT at room temperature and $573 \mathrm{~K}$ for 15 revolutions and (b) post-HPT annealing at $573 \mathrm{~K}$ for $30 \mathrm{~h}$.

\subsection{Hardness behavior at different homologous temperatures}

Based on the hardness measurements, Fig. 12 illustrates the summary of the present results. It is thus clearly demonstrated that there are three distinct types of hardness behavior in pure metals. First, at low homologous temperatures as room temperature in $\mathrm{Cu}$ [20], $\mathrm{Fe}$ [21], $\mathrm{Ti}$ [22], $\mathrm{Zr}$ [23] and $\mathrm{Hf}$ [24], the hardness increases with an increase in the equivalent strain at an early stage of straining but levels off and enters into a steady state where the hardness remains unchanged with further 
straining. Second, at moderate homologous temperatures as room temperature in Al [5,6,25-27], $\mathrm{Mg}$ [19] and $\mathrm{Zn}$, the hardness initially increases with increasing strain and, after reaching a maximum, decreases to a steady level. Third, at high homologous temperatures as room temperature in $\mathrm{Pb}, \mathrm{Sn}$ and $\mathrm{In}$, the hardness remains almost unchanged or slightly decreases with an increase in the equivalent strain at an early stage of straining and enters into a steady state at large strains.

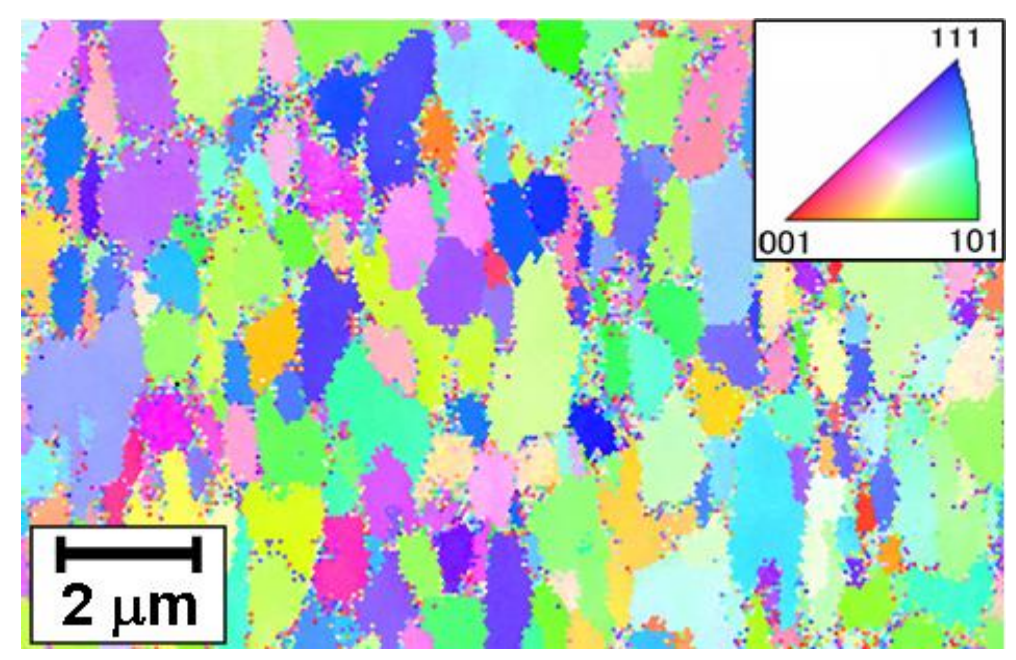

Fig. 11. EBSD orientation map for Pd after HPT processing for 15 revolutions at $573 \mathrm{~K}$ and post-HPT annealing at $433 \mathrm{~K}$ for $30 \mathrm{~h}$.

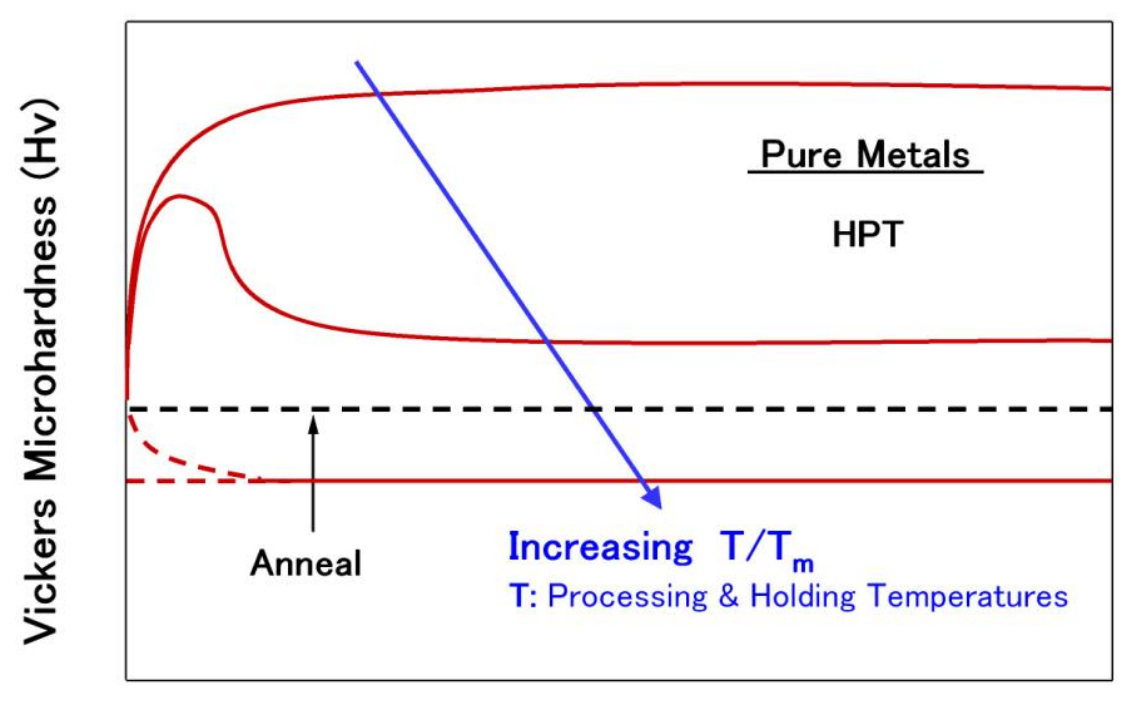

Equivalent Strain

Fig. 12. Illustration of hardness behavior of pure metals after HPT for different homologous temperatures.

At high homologous temperatures, the hardness at the steady state by HPT decreases below the hardness level of the annealed samples despite a moderate decrease in the grain size after the HPT processing and this is against the Hall-Petch relationship. It should be noted that the Hall-Petch 
relation is not valid at high homologous temperatures because of the effect of grain boundary sliding and the flow of vacancies. Thus, to clarify the reason for this decrease, the two additional measurements were carried out in this study. First, the hardness was measured on grain boundaries and grain interiors in Sn processed by HPT and compared with the average hardness, $6.9 \mathrm{Hv}$, in Fig. 5(b). It should be noted that the hardness values do not give the absolute hardness of grains and grain boundaries. However, since the indentation size is several times smaller than the grain size, a comparison between the two hardness measurements shows the effect of grain boundary. The hardness is $7.0 \mathrm{Hv}$ in the grain interiors and $6.4 \mathrm{Hv}$ on grain boundaries. Thus, the presence of grain boundaries can reduce the hardness in Sn.

Second, an HPT-processed In disc was annealed at $393 \mathrm{~K}$ for $1 \mathrm{~h}$ and its hardness was compared with the annealed sample prior to HPT. Following the annealing, the hardness of the HPT-processed disc increases from $1.4 \mathrm{Hv}$ to $1.7 \mathrm{Hv}$ which equals to the prior hardness of the annealed sample, 1.7 Hv. The results of these two experiments suggest that the lower hardness of the HPT-processed samples should be due to the contribution of grain boundaries which may act as a dislocation sink or cause grain boundary sliding to release strain hardening.

\subsection{Effect of homologous temperature and stacking fault energy on grain size}

Based on the hardness measurement and microstructural observation, it is clearly demonstrated that the homologous temperature and SFE are two important factors affecting the microstructural evolution in pure metals after HPT processing. On the one hand, the contribution of dynamic softening $\left(R_{D}\right.$ in Eq. (2)) increases with an increases in the homologous temperature and SFE. On the other hand, the dislocation mobility is high, and consequently, the static softening evolves much faster when the SFE is large [29]. However, close microstructural examinations indicate that although the SFE influence the microstructural evolution, the homologous temperature appears to be a more significant parameter influencing the steady-state grain size after processing by HPT.

Grain sizes at the steady state are plotted in Fig. 13 against the homologous temperature. The results reported for HPT-processed Ag (99.99\%) and Au (99.999\%) [38] are also included in Fig. 13 together with the result of an additional HPT experiment on Ni (99.996\%) after 10 revolutions in this study. It should be noted that room temperature corresponds to homologous temperatures of 0.24 for $\mathrm{Ag}, 0.22$ for $\mathrm{Au}$ and 0.17 for $\mathrm{Ni}$. It is apparent that the average grain sizes at the steady state are well represented by a unique function of homologous temperature. The grain size at the steady state increases monotonically with an increase in the homologous temperature. Here, in order to examine the effect of SFE on the average grain size, the grain sizes at the steady state are plotted in Fig. 14 against SFE for some given homologous temperatures. The results reported for HPT-processed Ag (99.99\%) and Au (99.999\%) [38] as well as Ni (99.996\%) are also included in Fig. 14. It should be noted that SFEs for $\mathrm{Ag}, \mathrm{Au}$ and $\mathrm{Ni}$ are 16,32 and $125 \mathrm{~mJ} \mathrm{~m}^{-2}$, respectively [20]. It appears that the final grain size is almost independent of SFE and this contrasts well with the grain size dependence on homologous temperature. The present result of the negligible dependence of SFE on the final grain size in HPT-processed metals disagrees with the report by Mohamed [30] in ball-milled metals and with the report by Zhao et al. [39] in HPT-processed alloys 
where the grain size decreases with decreasing SFE. It is important to note that the plots in Fig. 14 are made at given homologous temperatures for high purity metals. The contradiction arose because the effect of homologous temperature in Ref. [30] and the effect of solute atoms in Ref. [39] were not taken into account.

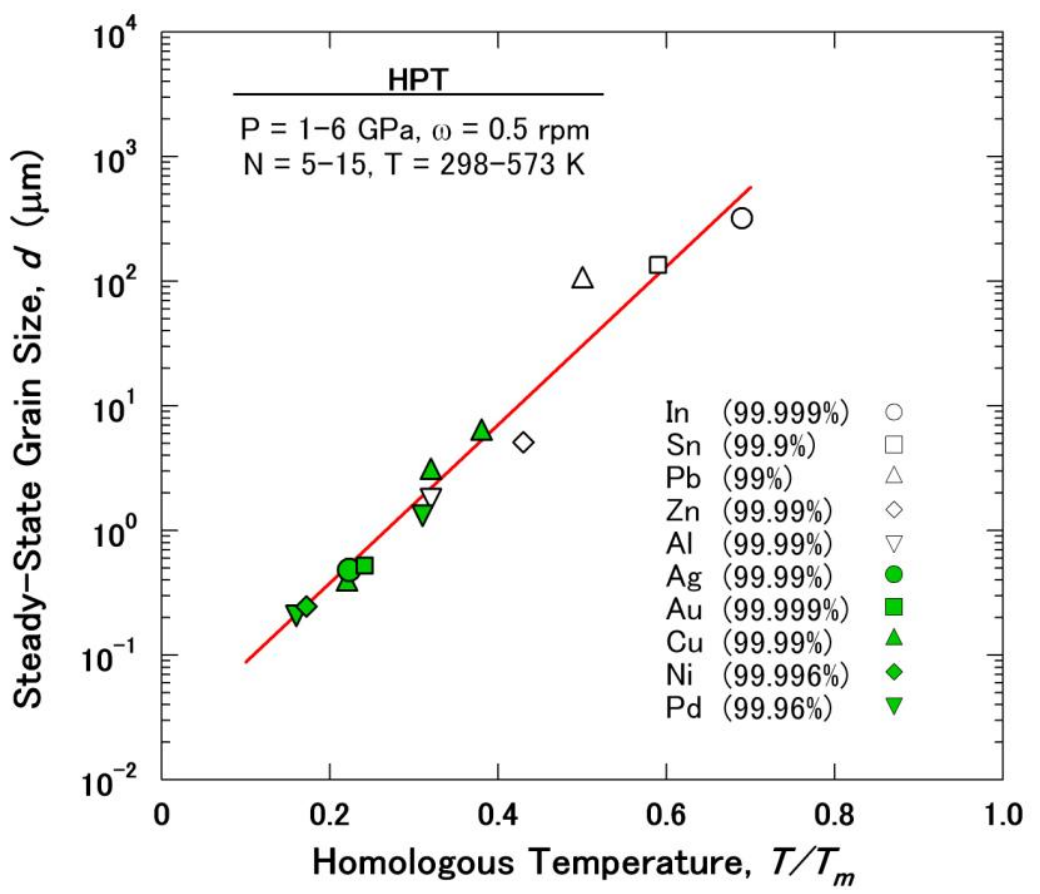

Fig. 13. Grain size at steady state, d, plotted against homologous temperature, T/Tm, for various pure metals. Data for Ag and Au were taken from Ref. [38].

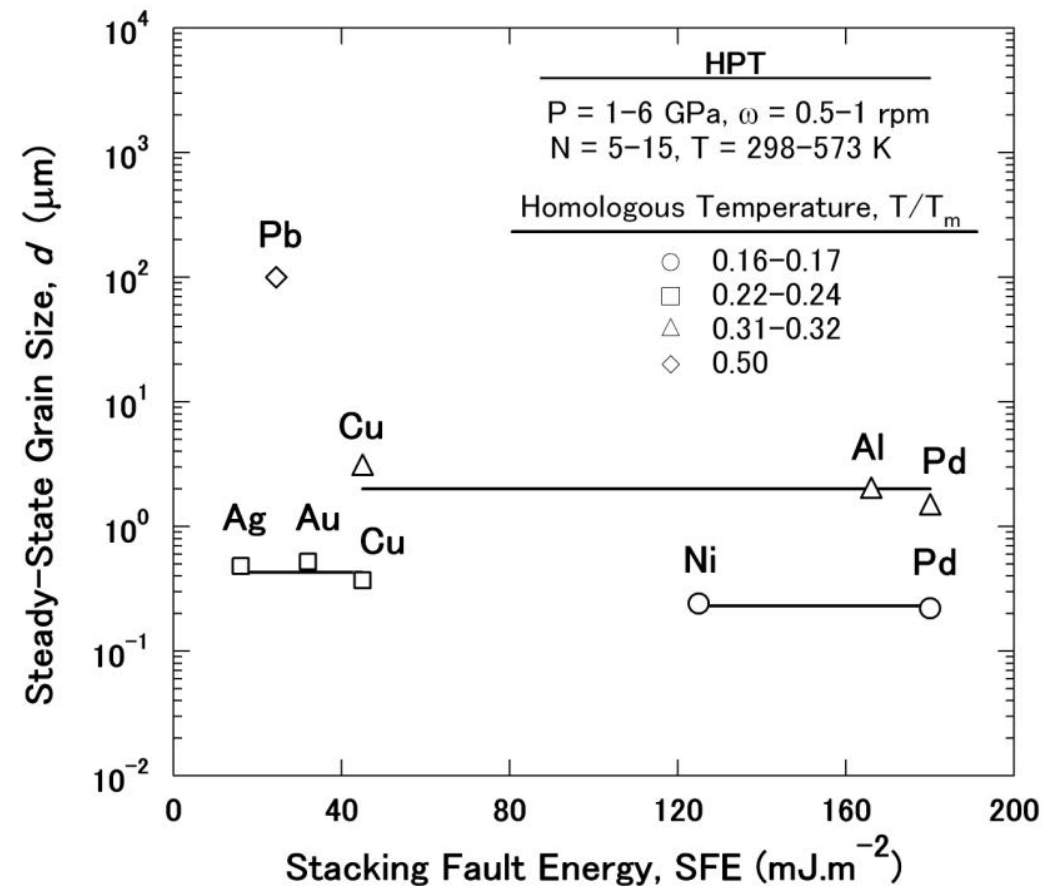

Fig. 14. Grain size at steady state, d, plotted against stacking fault energy, SFE, for various pure metals in various homologous temperatures. Data for $\mathrm{Au}$ and $\mathrm{Ag}$ were taken from Ref. [38]. 


\section{Conclusions}

High purity metals with low melting temperatures such as $\mathrm{In}, \mathrm{Sn}, \mathrm{Pb}, \mathrm{Zn}$ and $\mathrm{Al}$ were processed using high-pressure torsion (HPT) and the following conclusions were obtained.

1. A peak appears in $\mathrm{Al}$ and $\mathrm{Zn}$ when their hardness values are plotted against equivalent strain.

2. Pure $\mathrm{Cu}$ and $\mathrm{Pd}$ were used to simulate a thermal effect on the softening. It was shown that the hardness peak appears as in Al by static softening after processing by HPT.

3. Despite a moderate grain refinement in $\mathrm{Pb}, \mathrm{Sn}$ and $\mathrm{In}$, the hardness level at the steady state attained by HPT decreases below the hardness level of the annealed sample prior to HPT. This may be due to the contribution of grain boundaries acting as a dislocation sink or causing grain boundary sliding to release strain hardening.

4. As the homologous temperature increases, dynamic softening becomes important to decrease the hardness at the steady state. The homologous temperature is a dominant parameter to determine the steady-state grain size of pure metals processed by HPT.

5. The stacking fault energy (SFE) affects the dislocation mobility and the dynamic softening occurs more quickly to reach the steady state. However, the grain size at the steady is independent of the SFE at a given homologous temperature.

\section{Acknowledgements}

One of the authors (KE) thanks the Islamic Development Bank (IDB) for a doctoral scholarship and the Japan Society for Promotion of Science (JSPS) for a postdoctoral scholarship. This work was supported in part by the Light Metals Educational Foundation of Japan, in part by a Grant-in-Aid for Scientific Research from the Ministry of Education, Culture, Sports, Science and Technology of Japan in the Innovative Area "Bulk Nanostructured Metals", and in part by Kyushu University Interdisciplinary Programs in Education and Projects in Research Development (P\&P).

\section{References}

[1] R.Z. Valiev, R.K. Islamgaliev, I.V. Alexandrov, Prog. Mater. Sci. 45 (2000) 103-189.

[2] R.Z. Valiev, Y. Estrin, Z. Horita, T.G. Langdon, M.J. Zehetbauer, Y.T. Zhu, J. Met. 58 (4) (2006) 33-39.

[3] A.P. Zhilyaev, T.G. Langdon, Prog. Mater. Sci. 53 (2008) 893-979.

[4] P.W. Bridgman, Phys. Rev. 48 (1935) 825-847.

[5] Y. Harai, Y. Ito, Z. Horita, Scripta Mater. 58 (2008) 469-472.

[6] Y. Ito, Z. Horita, Mater. Sci. Eng. A 503 (2009) 32-36.

[7] R.Z. Valiev, Y.V. Ivanisenko, E.F. Rauch, B. Baudelet, Acta Mater. 44 (1996) 4705-4712.

[8] A.P. Zhilyaev, T.R. McNelley, T.G. Langdon, J. Mater. Sci. 42 (2007) 1517-1528.

[9] A. Vorhauer, R. Pippan, Scripta Mater. 51 (2004) 921-925.

[10] M. Hafok, R. Pippan, Philos. Mag. 88 (2008) 1857-1877.

[11] M. Hafok, R. Pippan, Int. J. Mater. Res. 101 (2010) 1097-1104.

[12] A.P. Zhilyaev, S. Lee, G.V. Nurislamova, R.Z. Valiev, T.G. Langdon, Scripta Mater. 44 (2001) 2753-2758. 
[13] Y. Todaka, Y. Miki, M. Umemoto, C. Wang, K. Tsuchiya, Mater. Sci. Forum 584-586 (2008) 597-602.

[14] B.J. Bonarski, E. Schafler, B. Milkulowskei, M.J. Zehetbauer, Mater. Sci. Forum 584-586 (2008) 263-268.

[15] A.V. Sergueeva, V.V. Stolyarov, R.V. Valiev, A.K. Mukhrjee, Scripta Mater. 45 (2001) $747-752$.

[16] Y. Todaka, J. Sasaki, T. Moto, M. Umemoto, Scripta Mater. 59 (2008) 615-618.

[17] G. Khatibi, J. Horky, B. Weiss, M. Zehetbauer, Int. J. Fatigue 32 (2010) 269-278.

[18] X.Z. Liao, Y.H. Zhao, S.G. Srinivasan, Y.T. Zhu, R.Z. Valiev, D.V. Gunderov, Appl. Phys. Lett. 84 (2004) 592-594.

[19] K. Edalati, A. Yamamoto, Z. Horita, T. Ishihara, Scripta Mater. 64 (2011) 880-883.

[20] K. Edalati, T. Fujioka, Z. Horita, Mater. Sci. Eng. A 497 (2008) 168-173.

[21] K. Edalati, T. Fujioka, Z. Horita, Mater. Trans. 50 (2009) 44-50.

[22] K. Edalati, E. Matsubara, Z. Horita, Metall. Mater. Trans. A 40 (2009) 2079-2086.

[23] K. Edalati, Z. Horita, S. Yagi, E. Matsubara, Mater. Sci. Eng. A 523 (2009) 277-281.

[24] K. Edalati, Z. Horita, Y. Mine, Mater. Sci. Eng. A 527 (2010) 2136-2141.

[25] C. Xu, Z. Horita, T.G. Langdon, Acta Mater. 55 (2007) 203-212.

[26] M. Kawasaki, B. Ahn, T.G. Langdon, J. Mater. Sci. 45 (2010) 4583-4593.

[27] M. Kawasaki, T.G. Langdon, Mater. Sci. Eng. A 498 (2008) 341-348.

[28] K. Edalati, Z. Horita, J. Mater. Sci. 45 (2010) 4578-4582.

[29] K. Edalati, Y. Ito, K. Suehiro, Z. Horita, Int. J. Mater. Res. 100 (2009) 1668-1673.

[30] F.A. Mohamed, Acta Mater. 51 (2003) 4107-4119.

[31] A. Buch, Short Handbook of Metal Elements Properties and Elastic Properties of Pure Metals, 3rd ed., Krzysztof Biesaga, Warasaw, 2005.

[32] J.P. Hirth, J. Lothe, Theory of Dislocations, 2nd ed., McGraw-Hill, New York, NY, 1968.

[33] T. Jossang, J.P. Hirth, Philos. Mag. 13 (1966) 657-670.

[34] K. Edalati, Z. Horita, T.G. Langdon, Scripta Mater. 60 (2009) 9-12.

[35] Y. Iwahashi, Z. Horita, M. Nemoto, T.G. Langdon, Acta Mater. 46 (1998) 3317-3331.

[36] M. Kawasaki, Z. Horita, T.G. Langdon, Mater. Sci. Eng. A 524 (2009) 143-150.

[37] Z. Horita, Proceedings of the 12th International Conference on Aluminum Alloys, The Japan Institute of Light Metals, Yokohama, 2010, pp. 40-45.

[38] H. Matsunaga, Z. Horita, Mater. Trans. 50 (2009) 1633-1637.

[39] Y.H. Zhao, Y.T. Zhu, X.Z. Liao, Z. Horita, T.G. Langdon, Mater. Sci. Eng. A 410-411 (2005) 188-193. 